\title{
Centros de memória no ambiente digital: em foco a análise de empresas públicas e privadas
}

\author{
Letícia Gorri Molina \\ Doutora, Universidade Estadual de Londrina, leticiamolina@uel.br \\ Cláudia Araki \\ Graduada, Universidade Estadual de Londrina, claudiaaraki86@gmail.com
}

\begin{abstract}
Resumo: Empresas demonstram a importância da preservação da memória empresarial por meio de Centros de Memória, relatando sua trajetória e englobando a comunidade em sua história. Como objetivo geral, pretendeu-se demonstrar como as empresas brasileiras segmentos públicos ou privados preservam sua memória empresarial em meio virtual. Objetivos específicos: analisar como estão estruturados os Centros de Memória Empresarial no ambiente virtual; verificar os tipos de documentação disponibilizados; fomentar a discussão acerca da importância dada pelas empresas aos seus Centros de Memória Empresarial. Esta pesquisa possui teor documental, exploratório e qualitativo; seu universo composto por 16 portais brasileiros, escolhidos intencionalmente, que possuíssem Centros de Memória Digital como fator comum. Como resultado, observa-se a importância dos portais no que diz respeito à preservação da memória de uma empresa, e evidencia-se que memória e arquivo caminham juntos, promovendo não somente a preservação da história de uma empresa, como também a preservação da história da sociedade.
\end{abstract}

Palavras-chave: Centros de memória. Memória empresarial. Preservação da memória.

\section{Introdução}

Quando estudamos a preservação da memória no ambiente empresarial, imediatamente pensamos na preservação da história de uma empresa ou instituição. No entanto, a preservação da memória empresarial vai além, significando também a preservação da memória da sociedade na qual a empresa está inserida.

A preocupação das empresas em preservar sua história tornou-se cada vez mais evidente ao longo das últimas décadas. Em resposta a isso, houve o 
início de uma mobilização com o intuito de criar e implantar Centros de Memória que, de acordo com Totini e Gagete (2004, p.124), “[...] constituem-se como setores responsáveis pela definição e aplicação de uma política sistemática de resgate, avaliação, tratamento técnico e divulgação de acervos." Além de utilizar estes centros como arquivos, a intenção seria também preservar as informações contidas nos documentos, transformando-as em fontes de pesquisa em diversas áreas.

Com a evolução da tecnologia, a produção documental aumentou massivamente tanto em suporte papel quanto digital. E se antes não havia preocupação na organização dos arquivos ou na administração de acervos, não havendo consciência em relação ao espaço físico, recuperação da informação e acesso e difusão da mesma aos usuários, isto acabou se tornando uma necessidade. Desta forma, tendo em vista que os documentos que estão sendo produzidos atualmente comporão a preservação como um todo, em todos os formatos e suportes, sua preservação não deve mais ser pensada somente em meio físico, mas também em meio digital.

De acordo com Halbwachs (2004), a diferença básica entre história e memória é que enquanto a primeira prende-se a fatos (história escrita), a segunda é aquela que cada indivíduo carrega (história vivida), formando um coletivo, compondo a sociedade.

A memória é o registro do passado, responsável por fazer com que lembremos de fatos ocorridos ao longo da vida, seus detalhes constituindo recordações. Um indivíduo é consciente do que vivenciou e dos conteúdos que ficam registrados em sua memória, guardados no seu subconsciente, passíveis de serem acionados por meio de elementos que despertem suas recordações. Como exemplo podemos citar as diversas formas de documento, que podem variar entre fotografias, cartas, imagens, etc. Partindo deste princípio, conclui-se que a memória empresarial pode ser considerada como um patrimônio da sociedade e que deve ser preservado para as futuras gerações. A falta de preservação de maneira devidamente adequada, acarreta em sua desestruturação e a torna passível de perda, transformando-a em um quebra-cabeças com peças 
faltando. É impossível contar uma história sem recorrer à elementos da memória.

Nas últimas décadas houve um aumento na produção de documentos, simultâneo à evolução tecnológica. As informações contidas nesses documentos, não só em suporte papel como também digitais não retratam apenas o que faz uma instituição ou suas atividades; esses documentos contam sua história ao longo de um período, também podendo ser utilizados como base da memória empresarial. E independente de qual seja o suporte, esta informação se encontra registrada em algum lugar, com a função é suprir a necessidade criada pela sociedade que pode querer recordar o passado. É por meio da informação que se registra o conhecimento e consequentemente se contribui para a construção da memória.

De acordo com Guarinello (1994, p. 185) “[...] deve falar do passado através de documentos que são também eles, bastante reais. Podemos coletá-los, consultá-los, analisá-los. É através da sua mediação, e só dela, que temos acesso às realidades passadas." Documentos trazem informações preciosas capazes de ajudar a descrever a história de uma instituição. A questão que permeia essa pesquisa é mostrar como empresas preservam sua memória, usando como objeto Centros de Memória Empresarial disponibilizados de forma virtual nos portais corporativos de empresas brasileiras e analisando-os.

Portais corporativos têm como objetivo maior disponibilizar informações a fim de auxiliar e facilitar a tomada de decisão na organização, porém não disponibilizam a informação estratégica propriamente dita. No entanto, possibilitam acesso restrito aos usuários habilitados, como por exemplo, os funcionários do nível tático e estratégico, às bases e bancos que possuem essas informações registradas. Como define Dias (2003, p. 3) eles propõem-se a "[...] oferecer uma mistura de conteúdo e serviços, tais como [...] mecanismos de busca, listas de discussão, por meio de uma interface compatível com seu público-alvo [...]".

Conforme defende Fontanelli (2005, p. 11), 
[...] trabalhar com a memória de uma empresa é trabalhar com as memórias de cada um de seus integrantes, que se reconhecem como tais e, assim, constroem as identidades individuais e a coletiva imprescindíveis para o desenvolvimento da instituição.

Como objetivo geral, pretendeu-se demonstrar de que maneira empresas brasileiras, sejam públicas ou privadas, disseminam sua memória dentro do meio virtual. Nos aspectos específicos desta pesquisa, teve-se como objetivo: a) analisar como estão estruturados os Centros de Memória Empresarial no ambiente virtual; b) verificar quais tipos de documentação é disponibilizado e c) discutir a importância que as empresas dão aos Centros de Memória Empresarial.

\section{Memória empresarial e Arquivologia}

A memória sempre esteve presente na sociedade, fazendo parte de sua construção. Quando uma empresa preocupa-se em preservá-la, ela cria um vínculo maior com as pessoas, pois faz com que elas participem da construção de sua memória. É como se as pessoas fizessem parte da construção da memória histórica dessa empresa, contribuindo com suas próprias lembranças.

Muitas empresas não direcionam a devida preocupação com o vínculo entre seus clientes e consumidores, talvez por desconhecerem a importância de preservar sua memória. No entanto, saber construir e manter esse vínculo por meio da memória é uma necessidade.

Ao falar sobre memória, é preciso analisar e delimitar a informação que deve ser adquirida e repassada. Le Goff (1990) disserta a respeito da importância da valorização da informação do presente e do passado como forma de registro com a utilização da memória. Para o autor,

[...] a memória, como propriedade de conservar certas informações, remete-nos em primeiro lugar a um conjunto de funções psíquicas, graças às quais o homem pode atualizar impressões ou informações passadas, ou o que ele representa como passadas. (LE GOFF, 1990, p. 423). 
A Memória Empresarial (ME) tem uma ligação com a Arquivologia uma vez que a primeira se concentra em construir o passado da empresa através da organização de documentos, mostrando para a sociedade a sua trajetória, enquanto a outra a auxilia na organização de "recortes do passado", informações valiosas colhidas de fontes variadas.

O processo de preservação da ME torna-se mais preciso por meio da Arquivologia, visto que se trata de uma ciência com fundamentos e conceitos, teorias concretas e ferramentas que auxiliam o arquivista na busca e acesso à informação, facilitando e agilizando o modo de organizar e armazenar os documentos a serem disponibilizados no centro de memória.

De acordo com Vitoriano (2005), mediante suas atividades e funções, uma instituição cria e acumula documentos durante sua existência, de maneira que para que se possa compreender um arquivo e sua estrutura, é necessário conhecer quem o produziu. Assim, pesquisar a história administrativa de uma instituição é essencial para que se possa entender suas funções e atividades, que fornecerão o contexto da sua produção documental.

Vê-se claramente o uso da Arquivologia na citação anterior, e pode-se complementar com as funções arquivísticas, que segundo Rousseau e Couture (1998, p. 265),

[...] deveriam examinar em profundidade cada uma das funções arquivísticas, ou seja, a criação, avaliação, aquisição, conservação, classificação, descrição e difusão dos arquivos. Repara-se que não se trata aqui de estabelecer distinções entre os arquivos correntes, os intermédios e os definitivos. Com efeito, as funções devem ser abordadas de modo a cobrir o conjunto dos princípios, dos métodos e das operações que se aplicam à organização e ao tratamento dos arquivos, independentemente da idade destes.

Observa-se que para uma empresa o cuidado com seus documentos, independente de seu suporte, é de suma importância desde sua criação até sua destinação final - que poderá ser o descarte (quando já não há mais valor administrativo, por exemplo) ou o arquivo permanente (quando ainda há valor histórico ou probatório para a empresa). 
Nessa direção, usando as funções arquivísticas corretamente, o trabalho de recuperação da memória da empresa será realizado de modo facilitado, já que os documentos estarão conservados, organizados, descritos, classificados e prontos para serem difundidos aos usuários.

Troitiño-Rodriguez (2012) considera a recuperação da história institucional de fundamental importância, visto que acredita ser reveladora das praxes e das transformações burocráticas e administrativas que perpassam as instituições ao longo de sua existência. Assim, o conhecimento de seu sistema organizacional, de forma a identificar suas funções, atividades e procedimentos, nos leva a compreender seus mecanismos de registro da informação e, consequentemente, contextualizar sua produção documental.

Neste contexto, observa-se que a empresa deve se adequar às tecnologias atuais e às que virão futuramente. Porém, sua história deve ser preservada por meio dos documentos que foram gerados ao longo de sua existência, como folders, contratos, compra de outras empresas, de outras marcas, fotografias, propagandas, etc.

De acordo com Nassar (2007) é importante a análise por parte dos gestores da organização acerca do que deverá ser selecionado no campo da memória, devendo-se pensar em quais espaços, momentos e condições serão realizadas estas seleções.

Não são somente os historiadores, pesquisadores, arquivistas, e restauradores que devem trabalhar para preservar essa memória empresarial. Os administradores, diretores, e diversos setores da empresa devem contribuir com este trabalho, incluindo também, familiares, clientes, funcionários e exfuncionários, comerciantes e consumidores - qualquer pessoa que teve algum tipo de ligação com a empresa e que contribua direta ou indiretamente para a construção da memória da mesma.

As informações devem ser pesquisadas, estudadas e classificadas, pois nem tudo será importante ou relevante para quem estiver interessado em saber mais a respeito da empresa. Seria interessante colher relatos dos clientes e consumidores, pessoas que se recordam de propagandas antigas, algo que tenha 
marcado uma época de sua vida, ou até mesmo colecionadores, pessoas que sintam uma admiração pela empresa.

Vitoriano (2011) relata que esses centros poderiam funcionar como repositório da memória da organização em sua faceta mais comum, a de artefatos, no sentido estrito do termo. Alguns exemplos de artefatos são fotos de eventos comemorativos, kits de integração de novos funcionários (os rituais), fotos de pessoas (tanto os heróis, quanto os anônimos), anúncios de propaganda e de ação social (os valores), relatos de história oral (histórias e mitos).

Sabe-se que a Arquivologia é multidisciplinar, podendo se relacionar com as mais diversas áreas do conhecimento. No caso de um centro de memória, pode funcionar como um arquivo técnico, voltado às áreas de Comunicação e Marketing. Estas áreas podem utilizar os documentos como forma de planejar novas propagandas - como propagandas comemorativas, por exemplo.

Vitoriano (2011, p. 101) ressalta que

Em busca de legitimidade e visibilidade, de comum acordo, todos envolvidos passam a tratar o centro como um arquivo técnico especializado na imagem da organização, nos seus mais diversos formatos e meios, de publicidade e propaganda a comunicação interna, passando por comunicação visual, relações institucionais com outras organizações, imagens da companhia na imprensa, entre outros conteúdos possíveis.

No entanto, é preciso lembrar que já que reúne informações valiosas de cunho científico e cultural, o centro de memória, além de um arquivo técnico, pode também ser utilizado para pesquisa em diversas áreas.

A ME tem seu foco maior nas áreas de Marketing, Relações Públicas e Comunicação, se consolidando como uma "[...] ferramenta de suporte a decisões e como instrumento relevante nas estratégias de comunicação e marketing das empresas." (SOUSA, 2010, p. 32).

Nassar (2004) afirma que os acervos das empresas são um tesouro, devendo ser preservados, já que fizeram e continuam fazendo parte do desenvolvimento da comunidade, além de promoverem os negócios e aumentarem a comunicação empresarial. 
Em relação a este contexto, Conway (2001) afirma que todos os suportes digitais utilizados como forma de preservação dos documentos são válidos, apesar de sua obsolescência, pois de uma maneira ou outra, acabam ajudando também na conservação dos documentos originais. Documentos valiosos, de valor histórico ou probatório, não necessitam ser manuseados com frequência, fazendo aumentar sua vida útil, já que muitos destes documentos já estão em decomposição, quebradiços e amarelados pelo tempo.

Como defende Hollós (2010) já há algum tempo que vivenciamos constantes rupturas onde o universo digital nos obriga a refletir o papel do conservador na sociedade da informação. Hoje, a informação que é gerada em meio eletrônico/digital, trafega em redes cada vez mais velozes e efêmeras, de modo que tem sido um dos maiores desafios para os Arquivistas e profissionais da Tecnologia de Informação (TI) preservar estas estruturas, ao menos em parte, em termos de conteúdo e ambiência tecnológica.

Conway (2001) afirma que a preservação por meio do universo digital, possibilita o uso da informação e protege o documento original, mas é necessário que se lembre que os objetos digitais também devem ser mantidos. Além de conservar e preservar os originais, é necessário também proteger as cópias digitais, colocando em uso uma prática denominada "preservação digital", algo que requer a constante migração dos arquivos digitais para outras mídias mais recentes de modo a garantir seu acesso.

Em relação à obsolescência dos formatos de armazenamento, Hollós (2010), defende que os equipamentos e softwares utilizados são substituídos rapidamente por versões mais recentes e o risco da obsolescência é o grande inimigo ainda não dominado. A forma digital, embora aparentemente se mostre bastante atrativa, rapidamente se torna obsoleta, exigindo uma preservação vigiada e permanente, com garantias de recursos materiais para as atualizações necessárias.

A diferença entre o documento em papel e o digital requer recursos tecnológicos, com o propósito de decifrar os bits em reproduções inteligíveis aos humanos. Por essa razão se faz importante plasmar para que a tecnologia é indispensável: ela possibilita o ingresso e leitura do objeto digital físico; para 
conhecer as normas empregadas para a codificação do elemento digital lógico e a decodificação para o elemento digital conceitual. Sem a tecnologia apropriada para acesso a esses dois objetos expostos, teria-se como consequência a perda total do conteúdo (YAMAOKA, 2012).

\section{Centros de memória no ambiente virtual}

Atualmente muitas empresas e instituições têm investido em portais e sites especializados em Centros de Memória com o objetivo de preservar sua história e torná-la acessível não apenas para seus colaboradores, mas também a quem possa interessar.

Algumas das empresas e organizações selecionadas para esta pesquisa, além do portal corporativo, disponível virtualmente, possuem o Centro de Memória em espaço físico, mantendo o centro em meio digital como forma de disseminar informação em qualquer parte do mundo onde existir um computador com acesso à internet.

Além da preservação da memória, estas empresas podem divulgar e valorizar sua marca, como forma de marketing, estreitar vínculos com consumidores, entre outros.

Os Centros de Memória apresentam uma estrutura mais complexa que, de acordo com Totini e Gagete (2004), além de resgatar, avaliar, fazer o tratamento técnico e divulgação dos acervos, também necessita analisar, de forma racional e sucessiva, o conhecimento produzido cotidianamente, sem que haja um acúmulo desnecessário, perda ou dispersão de documentos que comprovam a evolução da empresa, assim como fundamentam a formação de sua cultura, valores e capital intelectual.

Vê-se que cada parte da citação anterior remete à Arquivologia, pois a avaliação, tratamento técnico, divulgação, disseminação relacionam-se às metodologias e práticas arquivísticas. Também por meio da aplicação da teoria das três idades, estruturação e uso de tabela de temporalidade, além do plano de classificação, se evita o acúmulo de documentos desnecessários e os espaços podem ser otimizados para eventuais crescimentos orgânicos do acervo. 
Camargo (1999) defende que os Centros de Memória deveriam apresentar como característica fundamental a reunião, preservação e organização de arquivos e coleções, possuindo conjuntos documentais diversos, que seriam reunidos utilizando-se do critério de valor histórico e informativo, em torno de temas ou de períodos da história.

\section{Procedimentos metodológicos}

A presente pesquisa caracterizou-se como exploratória pois visa, conforme os objetivos propostos, descobrir, investigar e relatar como os sites das empresas ou corporações preservam sua memória.

Magalhães (2007, p. 27) afirma que este tipo de pesquisa é "[...] utilizada quando o tema é pouco explorado, quando há poucos conhecimentos, literaturas, informações sobre o problema a ser estudado. Proporciona uma visão geral, aproximativa do fato [...]", ou seja, procura-se fazer um estudo a fim de avaliar quais teorias ou conceitos podem contribuir para a pesquisa em questão.

A abordagem utilizada foi a quali-quantitativa. Em relação à abordagem qualitativa, Flick (2009, p. 25) defende que “[...] não se baseia em um conceito teórico e metodológico unificado. [...] Os pontos de vista subjetivos constituem um primeiro ponto de partida [...]", sendo aquela que objetiva gerar conhecimentos novos úteis para o avanço da ciência sem aplicação prática prevista.

Quanto à abordagem quantitativa, de acordo com Gil (2002, p. 133)

[...] depende de muitos fatores, tais como a natureza dos dados coletados, a extensão da amostra, os instrumentos de pesquisa e os pressupostos teóricos que nortearam a investigação. Pode-se, no entanto, definir esse processo como uma sequencia de atividades, que envolve a redução dos dados, a categorização desses dados, sua interpretação e a redação do relatório.

O método de pesquisa utilizado foi o documental, visto que se pretendeu demonstrar como essas empresas preservam sua memória, como um grupo que tem características em comum a preservação de sua história em meio virtual, já que os portais armazenam documentos, ainda que virtuais.

Conforme Gil (2002, p. 46) 
[...] na pesquisa documental, as fontes são muito mais diversificadas e dispersas. Há, de um lado, os documentos 'de primeira mão', que não receberam nenhum tratamento analítico. Nesta categoria estão os documentos conservados em arquivos de órgãos públicos e instituições privadas [...] como cartas pessoais, diários, fotografias, gravações, memorandos, regulamentos, ofícios, boletins etc.

Ainda segundo Marconi e Lakatos (2003), a pesquisa documental tem como característica principal a coleta de dados em documentos, escritos ou não, constituindo o que se denomina de fontes primárias - ou seja, documentos têm características únicas, e mesmo que não tenham sido analisados, são fontes ricas de informações.

Como universo de pesquisa delimitou-se empresas e instituições de grande porte do Brasil. Para especificar a amostra, localizou-se no site do Instituto Brasileiro de Geografia e Estatística (IBGE), empresas que possuem Centros de Memória. Desta forma, foram elencadas as 30 empresas que estão localizadas no portal do IBGE, em Outros centros de memória (INSTITUTO BRASILEIRO..., [2000?]). A partir daí, foram analisadas as empresas mais conhecidas e selecionadas, de forma intencional, $51 \%$ do universo, constituindose em 16 (dezesseis) empresas, de acordo com características como setor público, setor privado, diferentes segmentos empresariais e de mercado. Richardson (2007) defende que a amostra intencional precisa ter elementos relacionados intencionalmente de acordo com certas características estabelecidas no plano da pesquisa, assegurando a presença do sujeito-tipo, aquele que representa as características típicas de todos os integrantes que pertencem a cada uma das partes da população. Desta forma, a seleção das 16 empresas e instituições, em um total de 30 identificadas, possibilitou a abrangência de selecionar empresas de diferentes perfis e características.

Os sites selecionados para serem comparados nesta pesquisa foram públicos (ou de economia mista) - Memória SABESP (Companhia de Saneamento Básico do Estado de São Paulo), Memória Petrobras, Centro de Memória BM\&F BOVESPA (Bolsa de Valores, Mercadorias e Futuros de São Paulo), CEDEM/UNESP (Centro de Documentação e Memória da Universidade Estadual de São Paulo), Centro Histórico EMBRAER (Empresa Brasileira de 
Aeronáutica), Memória Receita Federal, Centro de Memória Digital Tribunal de Justiça do Distrito Federal e dos Territórios (TJDFT), Memória do IBGE - e privados - Centro de Memória Bunge, Memória Votorantim, Núcleo da Cultura Odebrecht, Centro de Memória Bosch, Centro de Memória TAM, Centro de História Unilever, Centro de Documentação e Memória Garoto, Centro de Memória Nestlé.

O instrumento de coleta de dados utilizado nesta pesquisa foi o checklist, aplicado aos portais/sites corporativos, comparando suas características com relação aos objetivos desta pesquisa. Por meio deste check-list, adaptado de Molina (2008), foi possível obter informações para a pesquisa, pois como dito anteriormente, trata-se de uma pesquisa exploratória de caráter qualitativo.

\section{Apresentação e discussão dos resultados}

O check-list foi aplicado em 16 portais corporativos, sendo estes divididos intencionalmente em dois grupos (públicos e privados) de diversos segmentos (alimentícios, construção civil, aviação, pesquisa estatística, tribunal da justiça, entre outros). A partir disso optou-se por comparar os portais públicos e privados.

\subsection{Centros de memória públicos}

Os portais corporativos dão suporte à empresa e a seus colaboradores nas tomadas de decisões, ao passo que disseminam informação e conhecimento aos seus usuários. No caso da presente pesquisa, os portais podiam ser temáticos, como os Centros de Memória, facilitando e agilizando o processo de busca, promovendo gestão de conteúdo de forma simples e objetiva, entre outros aspectos.

Segundo os dados coletados nos portais dos Centros de Memória públicos, 87,5\% fornecem dados cadastrais (endereço, telefone, fax, e-mail), seja do próprio Centro ou da Empresa/Órgão/Instituição. Porém estes dados apresentavam-se incompletos, constando ou o e-mail e telefone, ou endereço e 
telefone, ora no site, ora no portal. Importante ressaltar que os dados cadastrais foram coletados tanto no site, quanto no portal. Esse percentual também se mantém no conteúdo "quem somos" e "história da empresa". Apenas 38\% preocupam-se com "missão e valores" da corporação.

O uso de hipertexto é usado em $87,5 \%$ dos portais para dividir as informações em várias páginas ou níveis de detalhamento. Além disso, este mesmo percentual manteve-se com relação ao abrir de janelas adicionais.

Somente dois portais (Memória do IBGE e Centro Histórico EMBRAER) apresentam opção de link para conteúdo em outra língua, sendo esta a língua inglesa. Dos portais pesquisados, $87,5 \%$ fornecem algum tipo de mecanismo de busca em todas as páginas, mas apenas um portal (Memória SABESP) exibe uma página específica de busca - sendo esta uma busca avançada, na qual é possível combinar vários itens do acervo, como objetos, documentos textuais, imagens, pesquisa por palavras-chave e números.

Todos os portais restringem a busca ao seu ambiente interno, ou seja, qualquer palavra pesquisada remetia a algum conteúdo do portal ao acervo, ou então não existia nenhum resultado. Todos os links acessados em todos os portais públicos correspondiam corretamente ao seu conteúdo, ou seja, ao seu sistema de rotulagem.

Sete portais $(87,5 \%)$ oferecem opção de impressão, salvamento e download de arquivos, porém cada portal com suas peculiaridades. A Memória IBGE fornece o download em versão PDF (Portable Document FormatFormato Portátil de Documento) da Linha do Tempo e de outras publicações. A Memória SABESP, por sua vez, apenas os jornais. O Centro de Memória TJDFT disponibiliza biografias, composição plenária, entrevistas (história oral), o Centro Histórico EMBRAER a Revista Bandeirante, o Centro de Memória BM\&F BOVESPA boletins diários e o Memória Petrobrás documentos textuais. Somente a Memória da Receita Federal não ofereceu opções para download ou salvamento, e a impressão dá-se à página inteira - ao clicar no objeto ou documento, não é possível imprimi-lo.

Apenas 3 portais $(37,5 \%)$ fornecem campo para cadastro (CEDEM UNESP, Memória Petrobras, Centro de Memória BM\&F BOVESPA) para 
receber informações, notícias, acesso a conteúdos exclusivos, envio de material (contribuição) entre outros. 50\% ressaltam as palavras pesquisadas nos documentos.

Dos resultados dos mecanismos de busca, $75 \%$ possibilitam ser colocados em diferentes tipos de ordenamento, como mais antigos, mais recentes, alfabética ( $\mathrm{a}-\mathrm{z}$ ou $\mathrm{z}-\mathrm{a}$ ), por título, data de edição, data de submissão, decrescente ou ascendente, últimos seis meses, relevância e por data, por tipo de seção (artigos, depoentes, exposições virtuais, linha do tempo, entrevistas).

Todos os portais disponibilizam documentos iconográficos e textuais, e $75 \%$ de documentos em formato oral, além de audiovisuais, gráficos e objetos.Além disso, 87,5\%dos portais possuem um canal de comunicação como o "fale conosco" ou "contato".

Mais da metade $(62,5 \%)$ têm o Centro de Memória em espaço físico, sendo eles: Petrobras, IBGE, SABESP, TJDFT, EMBRAER, CEDEM UNESP. No portal do Centro Histórico EMBRAER é possível fazer uma visita virtual ao centro. A Memória SABESP localiza-se no próprio prédio da empresa no bairro da Ponte Pequena (SP). O portal Memória IBGE é um núcleo da Rede de Memória IBGE, coordenado pela equipe de Memória Institucional do Centro de Documentação e Disseminação de Informações, localizado no Rio de Janeiro, Bairro do Maracanã.

Percebe-se que os portais públicos dos Centros de Memória, em sua maioria, estão bem estruturados e arquitetados, porém oferecem poucos documentos para download, sendo estes em sua maioria documentos textuais, deixando imagens, áudios e vídeos apenas no formato online para os usuários.

\subsection{Centros de memória privados}

Conforme dados coletados no check-list de modo semelhante ao dos portais públicos, os Centros de Memória privados obtiveram 100\% dos dados cadastrais da empresa e $75 \%$ dos centros virtuais em termos de $e$-mail e telefone. Alguns destes portais na realidade podem ser considerados sites das empresas, que utilizam menus ou links para acessar o acervo, mas continuam na mesma página. 
Destes sites/portais, 87,5\% possuem conteúdo "quem somos", 50\% "missão e valores" e 100\% "história da empresa", podendo receber outras denominações, como "sobre a empresa" ou "nossa história", mas mantendo o sentido do termo.

No quesito acesso ao portal, 25\% (Núcleo da Cultura Odebrecht e Centro de Memória TAM) possuem página de abertura e link para pular esta mesma página. Mais da metade $(62,5 \%)$ apresentam mapa do site; $100 \%$ apresentam menu de navegação; 87,5\% possibilitam retornar à página anterior; 75\% usam hipertexto como meio de dividir as informações em níveis de detalhamento, e $50 \%$ abrem janelas adicionais.

Em relação ao conteúdo de usabilidade, apenas $25 \%$ apresentam link para conteúdo em outra língua (inglês e espanhol) sendo estes o Centro de Memória Bunge e o Núcleo de Cultura Odebrecht. Metade fornece mecanismos de busca em todas as páginas; $62,5 \%$ restringem a busca apenas ao conteúdo do portal. O Centro de Memória Nestlé, por fazer parte do site, restringe a busca ao site da Empresa Nestlé, e a Chocolates Garoto e o Centro de Memória TAM simplesmente não possuem opção de busca.

Alguns sites/portais (62,5\%) oferecem opção de download ou impressão, sendo a maioria apenas de documentos textuais- no entanto, alguns possibilitam a impressão da linha do tempo e/ou de livros da história da empresa. O portal do Núcleo da Cultura Odebrecht é apenas para uma visita virtual ao acervo, sendo que para fazer downloads o usuário precisa acessar o site da empresa, onde é possível fazer downloads de vídeos, fotos e infográficos, sendo também possível fazer compartilhamento nas redes sociais, através do menu "Centro de Mídia" em "Comunicação".

Apenas $25 \%$ fornecem campo para cadastramento no portal do centro; $50 \%$ não ressaltam as palavras pesquisadas nos documentos localizados por meio do sistema de busca, o que dificulta muito o trabalho do usuário em identificar a informação desejada. Além disso, $75 \%$ não possibilitou que os resultados de busca fossem colocados em ordem, e nos $25 \%$ restantes, não existe opção de busca. 
Nota-se que os documentos mais comuns são os textuais $(87,5 \%)$ e iconográficos (100\%). Documentos no formato oral foram encontrados em metade dos portais. Todos possuem canal de "fale conosco" ou "contato". O item mais relevante foi o fato de todos possuírem um Centro de Memória físico, mesmo dentro da empresa, em um espaço menor. A Chocolates Garoto têm o Museu do Chocolate em Vila Velha (ES); o Centro de Memória Nestlé localizase na fábrica da Nestlé em São Paulo; o Centro de Memória TAM fica no Museu TAM, em São Carlos, no estado de São Paulo; o Centro de História Unilever, na sede da empresa, em São Paulo; o Núcleo de Cultura Odebrecht é em Salvador, na Bahia); o Centro de Memória Bosch é mantido pelo Instituto Robert Bosch em Campinas, estado de São Paulo); a Memória Votorantim e o Centro de Memória Bunge também se encontram ambos em São Paulo.

\subsection{Principais comparações entre os portais de centros de memória públicos e privados}

Comparando os portais ou sites de Centros de Memória Públicos e Privados, nota-se que ambos não aparentam dar muita importância à Missão e Valores de sua Empresa ou Instituição. Enquanto nos portais públicos os dados cadastrais estavam sempre incompletos, nos portais privados era exatamente o contrário. Felizmente a maioria preocupa-se em ter um link no menu de navegação onde conta-se a história da empresa, também o conteúdo "quem somos" explicando o objetivo do portal. 
Quadro 1 - Comparação dos Portais na Categoria Usabilidade

\begin{tabular}{|l|c|}
\hline \multicolumn{2}{|c|}{ USABILIDADE DOS PORTAIS PÚBLICOS } \\
\hline Disponibiliza documentos iconográficos & $100 \%$ \\
\hline Disponibiliza documentos textuais & $100 \%$ \\
\hline Disponibiliza documentos no formato oral & $75 \%$ \\
\hline Fornece mecanismos de busca em todas as páginas & $87,5 \%$ \\
\hline $\begin{array}{l}\text { Oferece a opção de impressão, salvamento e download } \\
\text { do arquivo, de textos extensos }\end{array}$ & $87,5 \%$ \\
\hline $\begin{array}{l}\text { Possibilita que os resultados de busca sejam colocados } \\
\text { em ordem como, por exemplo: os mais relevantes, } \\
\text { cronológica crescente, cronológica decrescente, etc. }\end{array}$ & $75 \%$ \\
\hline 0 centro de memória possui espaço físico & $62,5 \%$ \\
\hline $\begin{array}{l}\text { Ressalta as palavras pesquisadas nos documentos } \\
\text { localizados por meio do sistema de busca }\end{array}$ & $50 \%$ \\
\hline
\end{tabular}

\begin{tabular}{|l|c|}
\hline \multicolumn{2}{|c|}{ USABILIDADE DOS PORTAIS PRIVADOS } \\
\hline Disponibiliza documentos iconográficos & $100 \%$ \\
\hline Disponibiliza documentos textuais & $87,5 \%$ \\
\hline Disponibiliza documentos no formato oral & $50 \%$ \\
\hline Fornece mecanismos de busca em todas as páginas & $50 \%$ \\
\hline $\begin{array}{l}\text { Oferece a opção de impressão, salvamento e download } \\
\text { do arquivo, de textos extensos }\end{array}$ & $62,5 \%$ \\
\hline $\begin{array}{l}\text { Possibilita que os resultados de busca sejam colocados } \\
\text { em ordem como, por exemplo: os mais relevantes, } \\
\text { cronológica crescente, cronológica decrescente, etc. }\end{array}$ & $25 \%$ \\
\hline O centro de memória possui espaço físico & $100 \%$ \\
\hline $\begin{array}{l}\text { Ressalta as palavras pesquisadas nos documentos } \\
\text { localizados por meio do sistema de busca }\end{array}$ & $50 \%$ \\
\hline
\end{tabular}

Fonte: Dados da pesquisa.

Todos os portais (com exceção da Empresa Garoto e Centro de Memória TAM, que não possuem opção de busca) restringem as buscas ao conteúdo do portal. É importante salientar que apenas $50 \%$ dos portais privados possuem mecanismos de busca em todas as páginas, enquanto que nos portais públicos são $87,5 \%$. Devido a isso, sugere-se que um portal que se destina à pesquisa de vários tipos de documentos e informações, pudesse fazer um campo de busca rápida em todas as páginas, facilitando e agilizando as pesquisas para os usuários.

Enquanto os portais públicos $(75 \%)$ permitiram colocar os resultados de busca em algum tipo de ordem (alfabética, por data, decrescente, crescente, entre outros), os portais privados (75\%) não possibilitaram essa função. Além disso, apenas $50 \%$ de ambos os portais ressaltam as palavras pesquisadas - uma ferramenta simples, porém importante, que facilita a visualização do documento e de seu conteúdo informacional.

Com relação às opções de download, impressão e salvamento, a grande maioria oferece esses recursos, contudo, estes conteúdos sempre são textuais (artigos, livros, linhas do tempo, revistas). Raramente conseguia-se fazer o 
download de uma imagem, de vídeos ou objetos tridimensionais. Para tal, era necessário clicar com o botão direito do mouse e selecionar a opção "salvar imagem como", e ainda assim nem todos os portais disponibilizavam esta "opção".

Os portais apresentaram várias tipologias documentais referentes aos seus segmentos, sendo a maioria no formato textual (acórdãos, processos históricos, livros, termos, coleções, publicações, artigos, jornais, anúncios impressos, embalagens, rótulos); iconográficos (imagens, fotografias, pinturas, gravuras, pôsteres, mapas, gráficos); objetos tridimensionais (copos, louças, talheres, uniformes, peças de vestuários comemorativas, entre outros); áudio, vídeo, depoimentos, entre outros.

Tanto os portais públicos $(62,5 \%)$ quanto os portais privados $(100 \%)$ mantêm Centros de Memória em espaços físicos, preservando a memória de sua empresa/instituição para a posteridade, utilizando os portais virtuais como formas de disseminar sua história, ampliando sua visibilidade diante a sociedade e seu acesso no meio virtual.

\section{Considerações finais}

A pesquisa realizada em portais brasileiros, analisando Centros de Memória públicos e privados, demonstrou que independente do segmento da corporação ou instituição, de algum modo há uma preocupação com sua memória e com a preservação de sua história, seja no ambiente virtual ou em espaços físicos, quando estas o possuem.

A maioria dos portais, tanto públicos quanto privados, tem sua estrutura organizada de forma clara e fácil para o usuário, subdividindo suas seções, contando a história da empresa/instituição e estruturando as informações em seus menus, facilitando e agilizando a pesquisa do usuário.

Também foi possível verificar quais documentos são disponibilizados nos portais, sendo a maioria em formatos textuais e iconográficos. Todavia, outros portais também possuem material disponível em áudio e em vídeo. 
De modo geral, a documentação está bem organizada, disposta por categorias de cada segmento empresarial, tipologias ou espécies. Pesquisando nos portais, foi possível descobrir que dentro dos centros em espaços físicos trabalham historiadores, arquivistas e documentalistas.

Ficou evidente que nos últimos anos o número de empresas que demonstraram interesse em organizar e disseminar sua história através dos centros de memória aumentou massivamente. Isso também foi transferido para o ambiente virtual, como maneira de divulgar a história empresarial para a sociedade.

Dos 16 portais pesquisados, constatou-se que a maioria aparenta dar a devida importância aos seus centros de memória virtual, promovendo a difusão de informação e acesso ao conhecimento da história da empresa - que consequentemente é parte da história do país.

Os portais devem ser constantemente atualizados com novas informações e documentos que surgirem ao longo do tempo - através de doações, por exemplo -, e também devem receber investimento na manutenção, melhoria e preservação da qualidade de seu suporte digital - fazendo uso de serviço qualificado para a construção e manutenção do portal, garantindo back-up do banco de dados e segurança das informações, por exemplo - da mesma maneira que se preserva seu suporte físico.

Ressalta-se que ambos os tipos de portais, ou seja, os públicos e privados, estão bem estruturados. As páginas são padronizadas, porém poderia se investir em campos de busca para os portais que ainda não os possuem; destacar as palavras nos resultados de busca; possibilitar o ordenamento dos resultados de busca em ordem (no caso dos portais privados); disponibilizar aos usuários o download (ou impressão) de todos os tipos de documentos, e não somente os textuais (e acrescentando marca d'água làs fotos como meio de proteger a fonte, por exemplo),; sugere-se também complementar os campos cadastrais (endereço, telefone, fax, e-mail), e incluir o campo "missão e valores" também seria interessante.

Os centros de memória virtual podem funcionar como uma extensão dos centros de memória físicos, sendo o portal uma forma de promoção da 
identidade institucional onde divulga-se a história da empresa e gera-se conhecimento a respeito da mesma, promovendo acesso e difusão de informação, e servindo não somente à sociedade como a si própria nas tomadas de decisões da empresa.

Os centros virtuais dão maior visibilidade para as empresas frente à sociedade, podendo ser acessados de qualquer lugar do mundo. Estes centros não preservam somente a memória mas também preservam conhecimento para o futuro da sociedade e da cultura do país.

Evidentemente, recomenda-se que outras pesquisas sejam realizadas sobre a temática para que exista um aprofundamento do tema para a área de Arquivologia, contribuindo assim para a abertura de novas indagações acerca do assunto.

\section{Referências}

CAMARGO,Célia Reis. Os centros de documentação das universidades: tendências e perspectivas. In: SILVA, Zélia Lopes da (Org.). Arquivos, patrimônio e memória: trajetórias e perspectivas.São Paulo: UNESP, 1999. p. 49-63.

CONWAY, Paul. Preservação no universo digital. 2. ed. Rio de Janeiro: Projeto Conservação Preventiva em Bibliotecas e Arquivos, 2001.Disponível em:

<http://www.portalan.arquivonacional.gov.br/media/CPBA_52_Preserva\%C3\% A7\%C3\%A3o_Universo_Digital.pdf>. Acesso em: 10 set. 2015.

DIAS, Claudia. Usabilidade na Web: criando portais mais acessíveis. Rio de Janeiro: Alta Books, 2003.

FLICK, Uwe. Introdução à pesquisa qualitativa. 3.ed. Porto Alegre: Artmed, 2009. (Métodos de Pesquisa).

FONTANELLI, Silvana Aparecida. Centro de memória e ciência da informação: uma interação necessária. 2005. 105 f. Trabalho de Conclusão de Curso (Graduação em Biblioteconomia) - Universidade de São Paulo, São Paulo, 2005. Disponível em:

<http://rabci.org/rabci/sites/default/files/Fontanelli-Memoria.pdf>. Acesso em: 10 set. 2015. 
GIL, Antônio Carlos. Como elaborar projetos de pesquisa. 4. ed. São Paulo: Atlas, 2002.

GUARINELLO, Norberto Luiz. Memória coletiva e história científica. Revista Brasileira de História Espaço Plural, São Paulo, v. 14, n. 28, p. 180-193, 1994.

HALBWACHS, Maurice. A memória coletiva. São Paulo: Centauro, 2004.

HOLLÓS, Adriana Cox. Preservação e memória social. In: SILVA, Rubens Ribeiro Gonçalves da et al. (Org.). Cultura, representação e informação digitais. Salvador: EDUFBA, 2010. p. 29-40.

INSTITUTO BRASILEIRO DE GEOGRAFIA E ESTATÍSTICA. Memória. Rio de Janeiro, [2000?]. Disponível em: <http://memoria.ibge.gov.br/sobrememoria/outros-centros-de-memoria>. Acesso em: 10 ago. 2014.

LE GOFF, Jacques. História e memória. Campinas: UNICAMP, 1990.

MAGALHÃES, Luzia Eliana Reis. O trabalho científico: da pesquisa à monografia. Curitiba: FESP, 2007.

MARCONI, Marina de Andrade; LAKATOS, Eva Maria. Fundamentos de metodologia científica. 5. ed. São Paulo: Atlas, 2003.

MOLINA, Letícia Gorri. Portais corporativos: tecnologias de informação e comunicação aplicadas à gestão da informação e do conhecimento em empresas de tecnologia de informação. 2008. 224f. Dissertação (Mestrado em Ciência da Informação) - Programa de Pós-Graduação em Ciência da Informação, Faculdade de Filosofia e Ciências, Universidade Estadual Paulista, Marília, 2008.

NASSAR, Paulo (Coord.). Memória de empresa: história e comunicação de mãos dadas, a construir o futuro das organizações. São Paulo: Associação Brasileira de Comunicação Empresarial, 2004.

NASSAR, Paulo. Relações públicas na construção da responsabilidade histórica e no resgate da memória institucional das organizações. São Paulo: Difusão, 2007.

RICHARDSON, Roberto Jarry. Pesquisa social: métodos e técnicas. 3.ed. rev. e ampl. São Paulo: Atlas, 2007.

ROUSSEAU, Jean-Yves; COUTURE, Carol. Os fundamentos da disciplina arquivística. Lisboa: Dom Quixote, 1998.

SOUSA, Sara Barbosa de. Memória empresarial: interesse utilitarista ou responsabilidade histórica? 2010. 146 f. Dissertação (Mestrado em Ciência da Informação) - Universidade de São Paulo, São Paulo, 2010. Disponível em: 
<http://www.teses.usp.br/teses/disponiveis/27/27151/tde-29102010-131012/>.

Acesso em: 10 set. 2015.

TOTINI, Beth; GAGETE, Élida. Memória empresarial, uma análise da sua evolução. In: NASSAR, Paulo (Coord.). Memória de empresa: história e comunicação de mãos dadas, a construir o futuro das organizações. São Paulo: Associação Brasileira de Comunicação Empresarial, 2004. p. 113-126.

TROITIÑO-RODRIGUEZ, Sonia Maria. A tipologia documental como instrumento para a seriação de documentos. In: VALENTIM, Marta Lígia Pomim (Org.). Estudos avançados em arquivologia. Marília: Oficina Universitária; São Paulo: Cultura Acadêmica, 2012. p. 243-258

VITORIANO, Maria Cristina de Carvalho Pazin. Arquivos de empresas: tipologia documental. São Paulo: Associação dos Arquivistas de São Paulo, 2005.

VITORIANO, Maria Cristina de Carvalho Pazin. Obrigação, controle e memória: aspectos legais, técnicos e culturais da produção documental de organizações privadas. 2011. 356 f. Tese (Doutorado em História Social) Universidade de São Paulo, São Paulo, 2011.

YAMAOKA, Eloi Juniti. Ontologia para mapeamento da dependência tecnológica de objetos digitais no contexto da curadoria e preservação digital. AtoZ, Curitiba, v. 1, n. 2, p. 65-78, jan./dez. 2012.

\title{
Memory centers in the digital environment: focus on the analysis of public and private companies
}

\begin{abstract}
Companies show the importance of preserving the organizational memory through Memory Centers, reporting its trajectory and encompassing the community in its history. As a general objective, it was intended to demonstrate how the Brazilian public and private sectors companies preserve their corporate memory in the virtual environment. Specific objectives: to analyze how are structured the Corporate Memory Centers in the virtual environment; checking the available types of documents; encourage discussion of the importance given by companies to their Corporate Memory Centers. This research has documental, exploratory qualitative content; his universe composed of 16 Brazilian portals, chosen intentionally possessing Digital Memory Centers as a common factor. As a result, there is the importance of the portals with regard to preserving the memory of a company, and it is evident that memory and file go
\end{abstract}


together, not only by promoting the preservation of the history of a company, as well as the preservation of history of society.

Keywords: Memory centers. Corporate memory. Preservation of memory.

Recebido: 23/09/2015

Aceito: 22/02/2016 